\title{
$\beta$-Adrenergic blockade is more effective in suppressing adrenaline-induced glucose production in Type 1 (insulin-dependent) diabetes
}

\author{
H. Shamoon ${ }^{1}$ and R. Sherwin ${ }^{2}$ \\ 'Department of Medicine and Diabetes Research and Training Center, Albert Einstein College of Medicine, Bronx, New York and \\ ${ }^{2}$ Department of Internal Medicine, Yale University School of Medicine, New Haven, Connecticut, USA
}

\begin{abstract}
Summary. To examine whether diabetes affects the ability of $\beta$-blockade to suppress adrenaline-stimulated hepatic glucose production, we infused adrenaline with and without propranolol into normal subjects and diabetic patients receiving a constant insulin infusion in basal amounts. In normal subjects, propranolol did not block the transient $50 \%-60 \%$ rise in glucose production during adrenaline infusion. In contrast, propranolol virtually abolished adrenaline-induced hyperglycaemia and glucose production was virtually abolished by propranolol in the diabetic patients, even though they demonstrated an exaggerated response to adrenaline alone (persistent increase in glucose production of $50 \%-90 \%$ above base-
\end{abstract}

line). When insulin was infused together with adrenaline and propranolol in normal subjects in doses exceeding those given to the diabetics (plasma insulin rose threefold), the rise in glucose production was still threefold greater than in the diabetic patients $(p<0.02)$. We conclude that $\beta$-blockade is more effective in suppressing the hepatic response to adrenaline in diabetics than in normal subjects. Our data may explain why diabetic subjects are more vulnerable to hypoglycaemia during treatment with propranolol.

Key words: $\beta$-blockade, propranolol, adrenaline, diabetes mellitus, glucose kinetics, liver, catecholamine action.
Physiological elevations of adrenaline cause a prompt increase in hepatic glucose production which occurs independent of a rise in plasma glucagon and a fall in plasma insulin [1,2]. The relative contribution of $\alpha$-adrenergic, calcium-dependent [3] and $\beta$-adrenergic, cyclic AMP-dependent pathways [4] to this action of adrenaline has been controversial. Recent studies have, however, suggested that adrenaline-stimulated hepatic glucose production in normal man is mediated predominantly, if not entirely, by $\beta$-adrenergic mechanisms [5, 6]. The failure of $\beta$-blockade to diminish the response of the liver to adrenaline in earlier studies in normal subjects has been attributed to concurrent suppression of endogenous insulin secretion secondary to unopposed $\alpha$-adrenergic stimulation [7].

It is not known whether diabetes affects the adrenergic mechanisms underlying the hepatic action of adrenaline or alters the ability of adrenergic blocking agents to limit adrenaline-induced hepatic glucose production. Previous studies have, however, shown that the hepatic response to adrenaline in Type 1 (insulin-dependent) diabetic patients differs both qualitatively and quantitatively from that in normal subjects [2]. Furthermore a number of clinical reports have suggested that the risk of hypoglycaemia is increased in diabetic patients treated with insulin and $\beta$-adrenergic blocking agents $[8,9]$. The latter might, at least in part, be explained by the inability of Type 1 diabetic patients to diminish insulin secretion when adrenaline is released and $\beta$-adrenergic receptors are blocked (unopposed $\alpha$ adrenergic stimulation).

The present study was therefore undertaken to evaluate the effect of $\beta$-adrenergic blockade on the hepatic response to adrenaline in normal and Type 1 diabetic subjects. To ensure that insulin levels were stable in the diabetic subjects throughout the experimental period, a constant infusion of insulin was administered in basal amounts. Because adrenaline-stimulated hepatic glucose production was more effectively suppressed in the diabetics, we infused exogenous insulin into the normal subjects together with adrenaline and propranolol. These latter studies were designed to assess whether prevention of the fall in portal insulin below baseline in normal subjects could resolve the disparity between normal and diabetic subjects.

\section{Material and methods}

\section{Subjects}

Two groups of subjects were studied. The first consisted of 19 normal subjects ( 12 males, 7 females) aged $20-32$ years and the second consisted of 15 Type 1 diabetic patients (11 males, 4 females) aged 


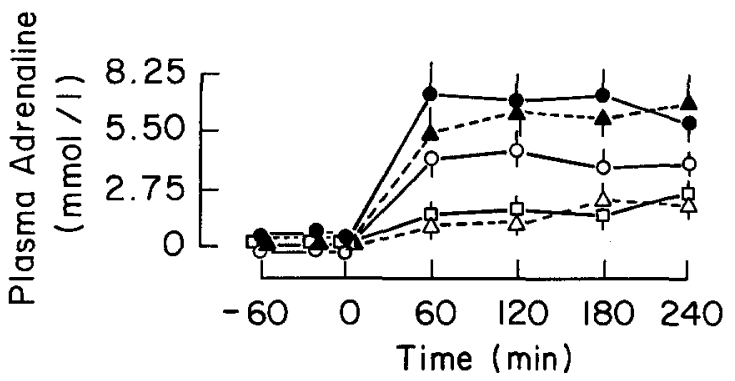

Fig. 1. Plasma adrenaline concentrations during experiments in normal subjects ( - ) and Type 1 diabetic patients ( $-\ldots)$. $\square-\square$ : normal subjects infused with adrenaline, $\mathrm{O}-\mathrm{O}$ : adrenaline + propranolol, or - adrenaline + propranolol + insulin are compared with $\Delta----\triangle:$ insulin-infused diabetic patients given adrenaline or $\Delta----\Delta$ : adrenaline + propranolol

18-31 years. All were within $20 \%$ of their ideal body weight (Metropolitan Life Insurance Tables, 1959) and consumed weight-maintaining diets containing at least $200 \mathrm{~g}$ of carbohydrate. The diabetic subjects were receiving a mean of $58 \pm 8$ units of insulin per $24 \mathrm{~h}$ in single $(n=6)$ or divided doses $(n=9)$ for $11 \pm 3$ years (mean \pm SEM). None of the subjects was taking drugs other than insulin and none had a history of asthma, heart disease or evidence of an intercurrent medical illness at the time of the study. After approval from the Committee on Clinical Investigation, informed written consent was obtained from each patient before each experiment.

\section{Procedures}

All subjects were studied in the morning, starting at $07.00-08.00 \mathrm{~h}$ after a $12-14 \mathrm{~h}$ overnight fast. Diabetic patients received no intermediate-acting insulin for at least $24 \mathrm{~h}$ before the study. An indwelling catheter was inserted into an antecubital vein in each arm for blood sampling and for continuous infusion (Harvard Apparatus, Millis, Massachusetts) of adrenaline, insulin, propranolol, and $\left[3-{ }^{3} \mathrm{H}\right]$-glucose. In normal subjects, $\left[3{ }^{3} \mathrm{H}\right]$-glucose (New England Nuclear, Boston, Massachusetts) was given as a primed-continuous infusion for $2 \mathrm{~h}$ before each experiment (equilibration period). The priming dose $(35 \mu \mathrm{Ci})$ was injected rapidly and followed by a constant infusion $(0.25 \mu \mathrm{Ci} / \mathrm{min})$ which was then continued throughout the study. In the diabetic subjects, crystalline zinc insulin (Eli Lilly, Indianapolis, Indiana) was infused at variable rates of $0.5-2.0 \mathrm{U} / \mathrm{h}$ in order to reduce plasma glucose concentrations gradually. After $1-4 \mathrm{~h}$, when plasma glucose values had fallen to approximately $8 \mathrm{mmol} / 1$, the rate of insulin infusion was further reduced (by 30\%-50\%) and a primedcontinuous infusion of $\left[3-{ }^{3} \mathrm{H}\right]$-glucose was begun. During the next $2 \mathrm{~h}$, the insulin infusion was finely adjusted to maintain normal plasma glucose concentrations (4-6 mmol/1). Thereafter, the insulin infusion was continued at a constant rate for an additional hour to ensure that plasma glucose levels were stable before baseline samples were obtained; this rate of insulin infusion was then continued for the remainder of the experiment. This rate averaged $0.13 \pm 0.03 \mathrm{mU} \cdot \mathrm{kg}^{-1} \cdot \mathrm{min}^{-1}$ in subjects infused with adrenaline alone and $0.11 \pm 0.02 \mathrm{mU} \cdot \mathrm{kg}^{-1}$. $\min ^{-1}$ in subjects infused with propranolol +adrenaline $(p=\mathrm{NS})$. The total equilibration period in the diabetic patients ranged from 4-7h.

After the equilibration period, three groups of studies were performed. In the first, adrenaline alone (Parke-Davis, Detroit, Michigan) was infused at a rate of $1.2 \mu \mathrm{g}-\mathrm{m}^{-2} \cdot \mathrm{min}^{-1}$ into 10 normal and eight diabetic subjects for $4 \mathrm{~h}$. In the second, propranolol (Inderal, Ayerst Laboratories, New York, USA) plus adrenaline $\left(1.2 \mu \mathrm{g} \cdot \mathrm{m}^{-2}\right.$. $\mathrm{min}^{-1}$ ) was infused into five normal and seven diabetic subjects. Propranolol was administered as a primed-continuous infusion $1 \mathrm{~h}$ before the addition of adrenaline to insure that adequate blood levels of propranolol were reached before the study [10]. Thereafter adrenaline was infused together with propranolol and both were continued for an additional $4 \mathrm{~h}$. Propranolol was given at a rate of $385 \mu \mathrm{g} / \mathrm{min}$ for
$25 \mathrm{~min}$ and then at a rate of $80 \mu \mathrm{g} / \mathrm{min}$ for the remaining $275 \mathrm{~min}$. In the third group of experiments, exogenous insulin was infused together with both propranolol and adrenaline into five normal subjects to avoid a decline in basal portal insulin concentration due to unopposed alpha-stimulation. The insulin infusion was initiated $58 \mathrm{~min}$ after the onset of the propranolol infusion, i.e. $2 \mathrm{~min}$ before the addition of adrenaline. Thereafter, propranolol, adrenaline and insulin were infused simultaneously for the remaining $4 \mathrm{~h}$ of the study. Insulin was administered at a rate of $0.15 \mathrm{mU} \cdot \mathrm{kg}^{-1} \cdot \mathrm{min}^{-1}$. We have reported previously on the amino acid responses to infusion of adrenaline alone and propranolol plus adrenaline in some of these subjects [11]. Due to the variable period of insulin infusion in diabetic subjects prior to the experiments, the adrenaline infusion in the diabetic patients was initiated 1-4h later than in the normal subjects.

The infusates were freshly prepared in sterile $\mathrm{NaCl}(0.154 \mathrm{~mol} / \mathrm{l})$. Ascorbic acid (Cevalin, Eli Lilly, Indianapolis, Indiana) was added to the adrenaline infusate at a concentration of $1 \mathrm{mg} / \mathrm{ml}$ to protect against oxidation. Insulin infusates contained $2 \mathrm{ml}$ of the subjects' whole blood per $50 \mathrm{ml}$ saline to prevent adherence to glassware and tubing [12]. Each infusate was administered by a separate syringe-type pump. Blood samples were drawn at $10-15 \mathrm{~min}$ intervals before the initiation of the experiment and at 15-30 min intervals thereafter.

\section{Analyses}

Plasma glucose concentration was measured by the glucose oxidase method using a Beckman glucose analyzer (Beckman Instruments, Fullerton, California). Plasma adrenaline was measured by an isotope-derivative technique [13], plasma immunoreactive insulin using a double-antibody method [14], and plasma non-esterified fatty acids (NEFA) using a colorimetric micromethod [15]. The methods used for determination of plasma immunoreactive glucagon (using Unger antibody $30 \mathrm{~K}$ ), and glucose specific activity have previously been described $[16,17]$. Plasma C-peptide reactivity was measured by radioimmunoassay in the insulin-infused normal subjects [18].

\section{Calculations}

The rates of endogenous glucose appearance and disappearance were calculated in the steady state before hormone infusion by the isotope dilution equation and during non-steady state conditions employing Steele's equations in their derivative form [19]. Derivative functions were calculated using a polynomial fitting method [20]. The value of 0.65 (pool fraction) was used to correct for non-instantaneous mixing within the entire glucose pool [21]. The measurement of glucose turnover rates based on the primed-continuous infusion tracer, the pool fraction technique and polynomial equations have been validated for both steady and non-steady states [22].

Statistical analyses were performed using an analysis of variance (ANOVA) to compare the response of different treatment groups over time. The Student's t-test was utilized to compare the difference between specific time points [23]. Data are presented as mean $\pm S E M$.

\section{Results}

\section{$\beta$-blockade and response to adrenaline in normal subjects}

The plasma adrenaline levels achieved during infusion of adrenaline alone and adrenaline plus propranolol are shown in Figure 1. Adrenaline alone produced a rapid rise in plasma adrenaline which reached a plateau within $60 \mathrm{~min}$. Between 1 and $4 \mathrm{~h}$ adrenaline levels averaged $1.85 \pm 0.20 \mathrm{nmol} / 1$. While the infusion of propranolol alone had no effect on basal adrenaline concentration before the addition of adrenaline $(0.105 \pm 0.022$ $\mathrm{nmol} / 1$ at $-60 \mathrm{~min}$ versus $0.099 \pm 0.017 \mathrm{nmol} / 1$ at 

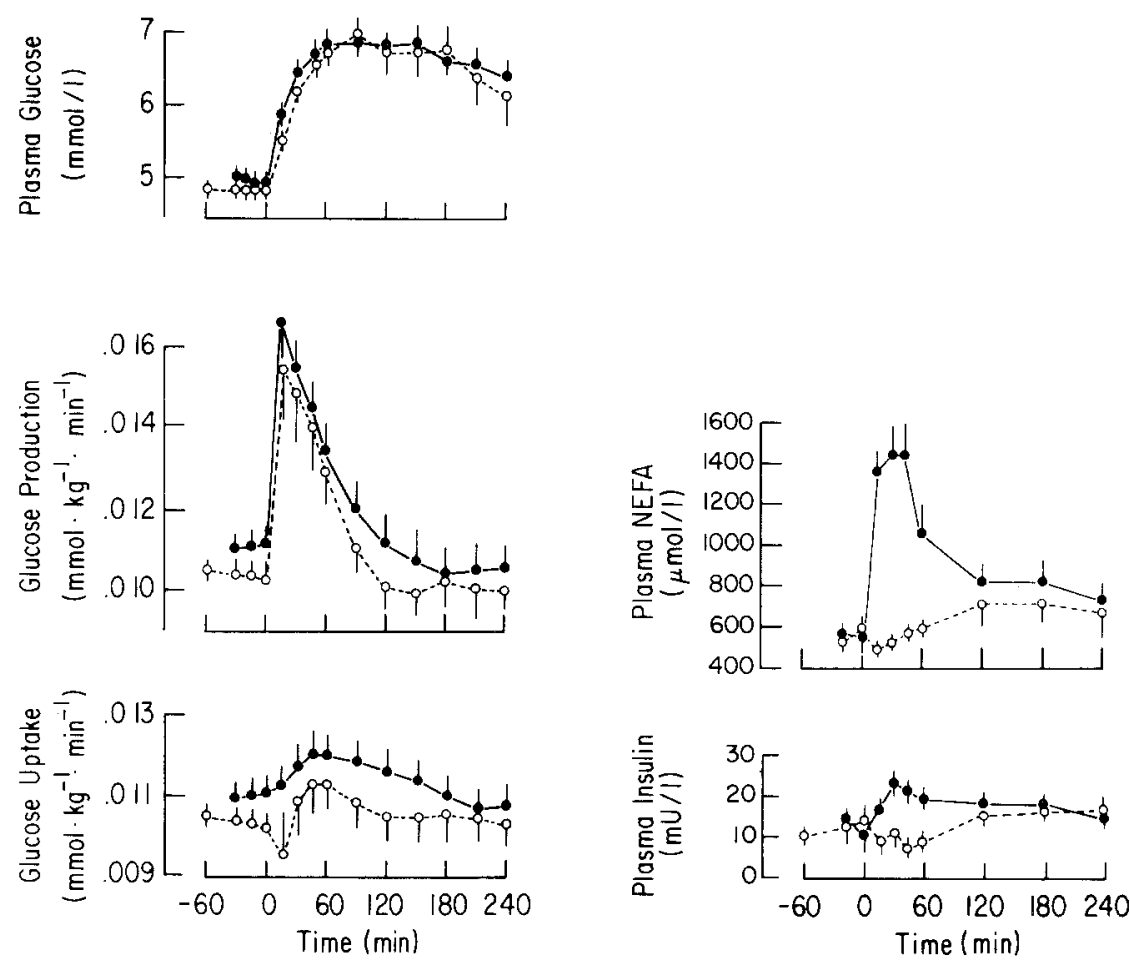

Fig. 2. Influence of $\beta$-blockade on the plasma glucose, non-esterified fatty acid (NEFA), insulin, and glucose kinetic response to adrenaline infusion in normal subjects. Adrenaline $(-0)$ or adrenaline plus propranolol $(\mathrm{O}----\mathrm{O})$ were infused for $4 \mathrm{~h}$

0 min, $p=\mathrm{NS}$ ), plasma adrenaline rose to levels two-to threefold higher when propranolol was infused compared with adrenaline alone. Similar results were also obtained when insulin was added to the adrenaline plus propranolol infusion. For all the adrenaline plus propranolol studies in normal subjects, including those in which insulin was added, plasma adrenaline averaged $5.066 \pm 0.55 \mathrm{nmol} / 1$ between 1 and $4 \mathrm{~h}$ (Fig. 1).

As shown in Figure 2, propranolol pre-treatment had no effect on plasma glucose or glucose kinetics in the 60 -min period before the addition of adrenaline. More importantly, neither the rise in plasma glucose nor the changes in glucose appearance and disappearance induced by adrenaline were altered by propranolol administration. In both groups, glucose appearance rose by $50-60 \%(p<0.001)$ and then returned to baseline by $90-120 \mathrm{~min}$; glucose disappearance increased slightly, but not significantly. In marked contrast, the two-to threefold rise in plasma NEFA caused by infusion of adrenaline alone $(p<0.001)$ was totally abolished by the addition of propranolol (Fig. 2).

The effect of propranolol on the plasma insulin response to adrenaline infusion is shown in Figure 2. During the first $60 \mathrm{~min}$, plasma insulin concentration tended to rise after adrenaline alone and tended to fall after the combined adrenaline-propranolol infusion. Although the changes from baseline over the $4 \mathrm{~h}$ experiments were not significant (ANOVA), when the two groups were compared at 30-60 min plasma insulin levels were significantly different $(p<0.005)$. Plasma glucagon concentrations were unchanged by either adrenaline or adrenaline plus propranolol infusion (Table 1 ).

\section{$\beta$-blockade and adrenaline-induced glucose production in diabetic subjects}

As in normal subjects, the propranolol infusion had no effect on basal adrenaline levels, but caused a three-to fourfold greater rise in plasma adrenaline concentration during the infusion of adrenaline than with adrenaline alone $(6.424 \pm 0.759$ versus $1.766 \pm 0.132 \mathrm{nmol} / 1$ between 1 and 4 h, $p<0.001$; Fig. 1). Before adrenaline administration, plasma glucose levels were maintained in the normal range by the basal insulin infusion and were not significantly altered by propranolol administration (Fig. 3). When adrenaline alone was infused in the diabetic patients, plasma glucose increased by $6.11-6.66$ versus $1.67-1.94 \mathrm{mmol} / 1$ in normal subjects and glucose appearance rose by $50-90 \%$ above baseline throughout the 4 h study ( $p<0.001$; Fig. 3 ). Both the rise in plasma glucose and glucose appearance after $1 \mathrm{~h}$ were significantly greater in the diabetic patients compared with normal subjects $(p<0.001)$. Glucose disappearance, however, failed to increase in spite of hyperglycaemia until the plasma glucose exceeded $10 \mathrm{mmol} / 1$. Even though the hepatic response to adrenaline alone was exaggerated in the diabetic patients, propranolol infusion virtually abolished the rise in plasma glucose and glucose appearance produced by adrenaline. Glucose appearance initially rose slightly by $10-15 \%$ at $15 \mathrm{~min}$ $(p<0.005)$ but rapidly returned to pre-infusion values within $30 \mathrm{~min}$. Glucose disappearance closely paralleled the changes in glucose appearance. Plasma glucagon levels were unchanged during infusion of adrenaline whether or not propranolol was added (Table 1). 
Table 1. Plasma glucagon concentration (pmol/l) during infusions of adrenaline, adrenaline plus propranolol, and insulin in normal and diabetic subjects

\begin{tabular}{|c|c|c|c|c|c|c|c|c|c|c|}
\hline Infusions & \multicolumn{10}{|c|}{ Infusions at time (min) } \\
\hline \multicolumn{11}{|l|}{ Normal subjects } \\
\hline $\begin{array}{l}\text { Adrenaline + } \\
\text { propranolol }\end{array}$ & $21.2 \pm 4.0$ & $23.2 \pm 1.4$ & $22.7 \pm 2.0$ & $24.7 \pm 0.9$ & $25.3 \pm 2.3$ & $24.7 \pm 4.9$ & $29.3 \pm 3.7$ & $24.4 \pm 0.9$ & $26.1 \pm 3.7$ & $25.3 \pm 3.4$ \\
\hline \multicolumn{11}{|l|}{ Diabetic patients } \\
\hline Adrenaline & - & $29.8 \pm 6.6$ & $28.7 \pm 6.6$ & $35.0 \pm 8.3$ & $33.9 \pm 7.2$ & $34.7 \pm 8.3$ & $34.4 \pm 5.7$ & $32.4 \pm 6.9$ & $30.1 \pm 6.0$ & $29.3 \pm 5.2$ \\
\hline $\begin{array}{l}\text { Adrenaline }+ \\
\text { propranolol }\end{array}$ & $46.5 \pm 9.8$ & $37.6 \pm 5.5$ & $43.3 \pm 5.7$ & $42.7 \pm 4.9$ & $40.2 \pm 4.3$ & $44.5 \pm 3.2$ & $42.7 \pm 5.7$ & $41.9 \pm 5.2$ & $41.9 \pm 5.7$ & $39.0 \pm 5.7$ \\
\hline
\end{tabular}

Values are expressed as mean \pm SEM. ${ }^{\text {a }} p<0.01$

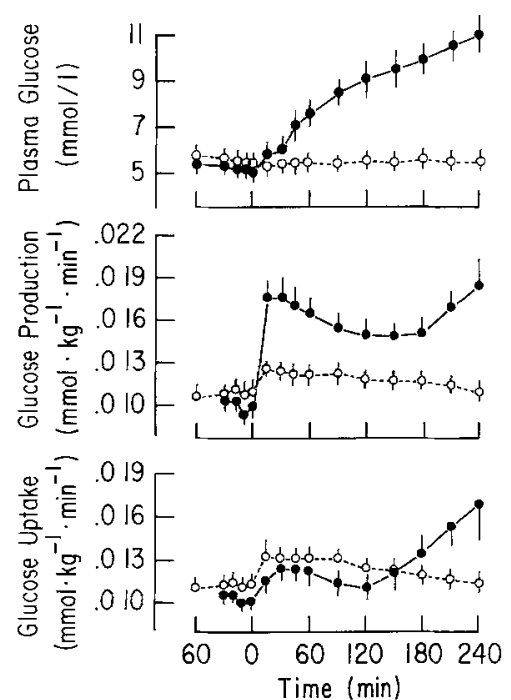

Fig.3. Influence of propranolol on the response of glucose kinetics to adrenaline infusion in Type 1 diabetic subjects. $-=$ adrenaline; $\mathrm{O}-\mathrm{O}_{\mathrm{O}}=$ adrenaline plus propranolol. Diabetic patients were initially infused with insulin for 4-6h to normalize plasma glucose and thereafter insulin (mean dose $0.12 \mathrm{mU} \cdot \mathrm{kg}^{-1} \cdot \mathrm{min}^{-1}$ ) was continued throughout each experiment

\section{Exogenous insulin replacement plus $\beta$-blockade and adrenaline-induced glucose production in normal subjects}

To examine whether the fall in insulin in normal but not diabetic subjects could account for the greater effectiveness of $\beta$-blockade in the diabetic patients, we infused insulin into normal subjects to maintain circulating insulin at least above baseline during the infusion of adrenaline and propranolol. As shown in Figure 4, the exogenous insulin infusion resulted in a threefold rise

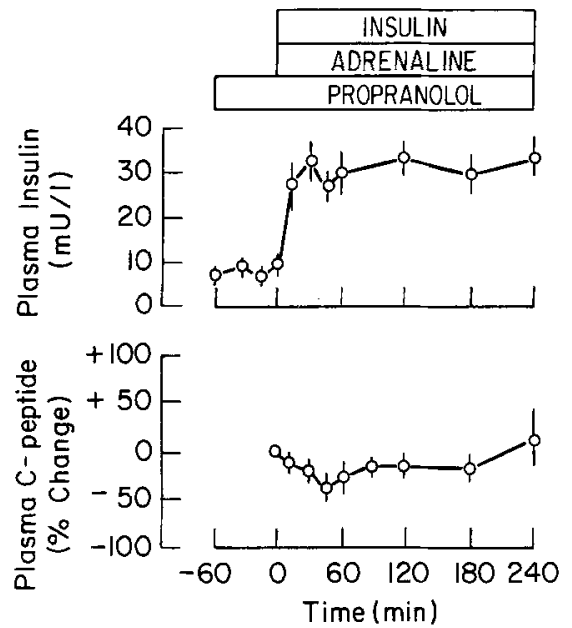

Fig.4. Effect of exogenous insulin infusion $\left(0.15 \mathrm{mU} \cdot \mathrm{kg}^{-1} \cdot \mathrm{min}^{-1}\right)$ on plasma insulin concentration and the changes in plasma C-peptide levels from basal values during combined infusion of propranolol and adrenaline

in plasma insulin from $10 \pm 2$ to a plateau of $32 \pm 7$ $\mathrm{mU} / 1$ between $30-240 \mathrm{~min}(p<0.001)$. On the other hand, C-peptide concentration $(0.56 \pm 0.2 \mathrm{pmol} / \mathrm{ml}$ basal) fell by $20 \%-30 \%(p<0.05)$, but not sufficiently to cause an absolute reduction of portal venous insulin concentration (Fig. 4). As shown in Figure 5, plasma glucose levels rose by $0.3-0.6 \mathrm{mmol} / 1$ for $90 \mathrm{~min}(p<$ 0.01 ) and then gradually declined to values $0.6-0.8$ $\mathrm{mmol} / 1$ below baseline at $210-240 \mathrm{~min}(p<0.05)$. Despite the elevated insulin levels and the concomitant propranolol infusion, adrenaline produced an immedi- 

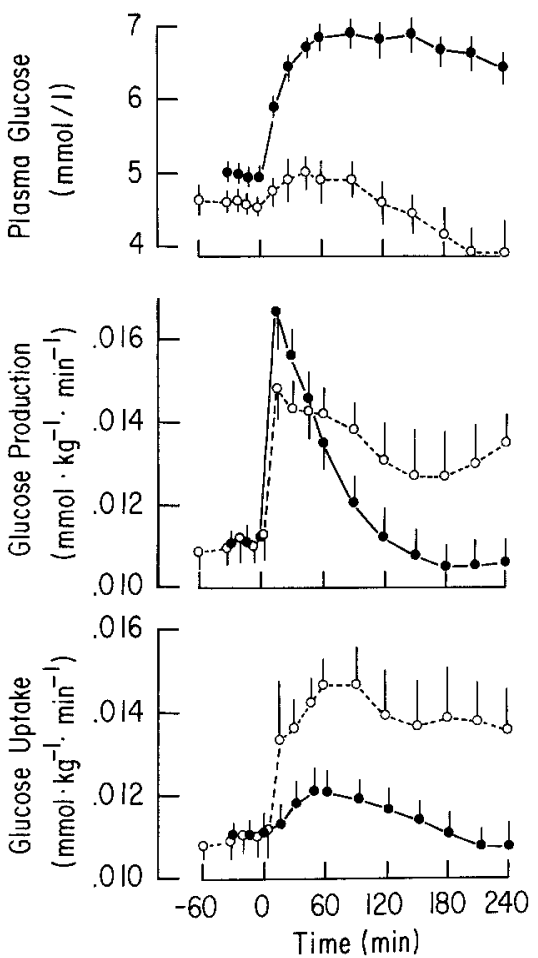

Fig.5. Effect of a combined propranolol and insulin $(0.15 \mathrm{mU}$. $\mathrm{kg}^{-1} \cdot \mathrm{min}^{-1}$ ) infusion on the response of glucose kinetics to adrenaline infusion in normal subjects. $-=$ adrenaline alone; O---- $\mathrm{O}=$ adrenaline + propranolol + insulin
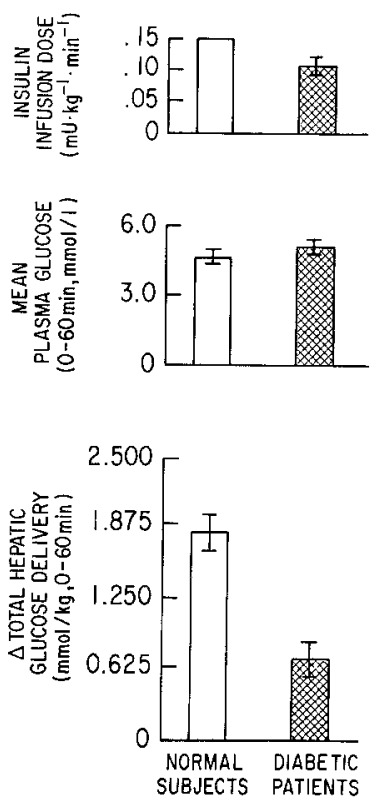

Fig. 6. Disparate effect of $\beta$-blockade in normal subjects and Type 1 diabetic patients. Total hepatic glucose delivery above basal during the first hour of the study in the diabetic patients is compared with that in normal subjects receiving a high-dose insulin infusion. In the normal group, the rates of exogenous insulin infusion and the mean plasma glucose concentration during the first hour were comparable to those in the diabetic patients. Nevertheless, the rate of glucose release in response to adrenaline infusion was significantly greater than in the diabetic group ate $40 \%$ rise in glucose appearance $(p<0.001)$, which was not significantly reduced compared with that observed with adrenaline alone (Fig. 5). Thereafter, glucose appearance gradually declined by $0.001 \mathrm{mmol}$. $\mathrm{kg}^{-1} \cdot \mathrm{h}^{-1}$ for $2 \mathrm{~h}$ and then remained $20 \%-25 \%$ above baseline ( $p<0.005$ between $120-240 \mathrm{~min}$ ) when plasma glucose fell below basal values. On the other hand, the addition of insulin resulted in a 30\%-35\% increase in glucose uptake which minimized the rise in plasma glucose concentration $(p<0.001 ;$ Fig. 5). Plasma glucagon concentration increased significantly by $60 \%-65 \%$ between $180-240$ min coinciding with a rise in glucose production (Table 1 ).

Figure 6 summarizes the effect of $\beta$-blockade on the response to adrenaline in normal subjects given insulin and the insulin-infused diabetic patients. In spite of comparable rates of exogenous insulin infusion (actually slightly lower in the diabetic group) and identical plasma glucose concentrations in the initial $60 \mathrm{~min}$ of the combined adrenaline plus propranolol infusion, normal subjects exhibited a more pronounced rise in glucose appearance. During this time interval $(0-60 \mathrm{~min})$ the total amount of glucose released from the liver (above baseline) was threefold greater in the normal than in the diabetic group ( $p<0.02$; Fig. 6$)$.

\section{Discussion}

In this study, as reported previously [7], the increase in hepatic glucose production induced by adrenaline in normal subjects was not abolished by the $\beta$-adrenergic blocking agent, propranolol. In contrast, identical doses of propranolol were considerably more effective in inhibiting the hepatic action of adrenaline in Type 1 diabetic patients receiving a constant infusion of insulin in basal amounts. The latter observation is consistent with earlier studies by Gerich et al. [24] showing that propranolol attenuated, but did not block the glycaemic response to adrenaline in hyperglycaemic diabetic subjects. However, in those studies the effect of $\beta$-blockade was totally ascribed to suppression of adrenaline-induced hyperglucagonaemia [24]. This confounding variable was minimized in the current study by using smaller doses of adrenaline and exogenous insulin to correct hyperglycaemia in the diabetic subjects [2]. Several other potential explanations for the greater effectiveness of $\beta$-blockade in the diabetic group may also be excluded. Comparable degrees of $\beta$-adrenergic activity were common to both groups, since plasma adrenaline levels were similar. Circulating glycogenic amino acids have been shown to be comparable in normal and diabetic subjects during these infusions of adrenaline and propranolol [11]. Lastly, the effect of propranolol in the diabetics cannot be attributed to indirect suppression of hepatic glucose production by hyperglycaemia per se [25], since plasma glucose failed to rise during com- 
bined adrenaline/propranolol infusion in the diabetic patients.

The apparent disparate response to $\beta$-blockade in normal and diabetic subjects may be due to differences in circulating insulin levels since in the diabetics insulin delivery was fixed, whereas in normal subjects, systemic (and presumably portal) insulin levels tended to decline due to unopposed $\alpha$-adrenergic stimulation. This conclusion is, however, not entirely supported by the insulin replacement experiments (Fig.3). When exogenous insulin was infused into normal subjects to prevent an absolute fall in circulating insulin below baseline, the rise in hepatic glucose production continued to exceed that observed in the diabetic patients. Since the doses of insulin used were slightly greater than those administered to the diabetic group and endogenous insulin secretion was only partially suppressed by the exogenous insulin infusion (Fig.4), portal insulin levels should have been higher in the normal as compared to the diabetic subjects. Although 'free' insulin levels were not measured in this study, this assumption is supported by other studies from our laboratory showing that circulating 'free' insulin concentrations are no greater, and indeed tend to be lower, during exogenous insulin infusion in Type 1 diabetic patients compared with normal subjects [26].

It should be emphasized that our data in no way imply that $\alpha$-adrenergic mechanisms are the predominant pathways mediating adrenaline-induced hepatic glucose production in normal subjects and do not allow for comparison of the relative potencies of $\alpha$ - and $\beta$-adrenergic stimuli in this group. Utilizing differing experimental designs, others have shown that glucose production in normal man is mediated predominantly by $\beta$-adrenergic mechanisms [5,6] though $\alpha$ mechanisms also play a role $[5,7]$. Our data clearly do not refute these observations. Indeed, our experimental design may have served to accentuate the hepatic effects of $\alpha$ adrenergic stimulation in normal subjects. When insulin was infused with propranolol and adrenaline, the rise in plasma glucose was markedly attenuated. As a consequence, the $\alpha$-adrenergic stimulation of glucose production may have been enhanced by the lack of the restraining influence of hyperglycaemia per se on glucose output [25]. In addition, it is probable that some degree of relative hypoinsulinaemia still existed in the insulininfused normal subjects. Since the ratio of portal to peripheral plasma insulin levels is approximately $3: 1$ [27], we can estimate that portal venous insulin concentration was approximately $30 \mathrm{mU} / 1$ in the basal state. If we assume that $\mathrm{C}$-peptide concentrations in the insulin replacement studies are directly related to insulin secretion [28], then the endogenous contribution to portal insulin levels should be approximately $20 \mathrm{mU} / 1$. When the contribution of the infused insulin is also taken into consideration (approximately $25 \mathrm{mU} / 1$ ), the net result amounts to a portal insulin concentration of $45 \mathrm{mU} / 1$. Such values, while clearly above baseline, are likely to be lower than those during infusion of adrenaline alone. Regardless of the above considerations, it should be noted that these same conditions that would tend to promote $\alpha$-adrenergic stimulation of glucose production in the normal subjects (absence of hyperglycaemia and relative portal hypoinsulinaemia) also occurred in the diabetic patients. It is conceivable, therefore, that the diabetic state may cause a relatively greater dependence of $\beta$-adrenergic mechanisms for adrenaline-stimulated hepatic glucose production. Of interest in this regard, both thyroid hormone [29-31] and insulin [32] have been shown to influence the relative proportion of $\alpha$ - and $\beta$-adrenergic receptors.

Our findings may have important clinical implications concerning the use of $\beta$-blocking agents in Type 1 diabetes. Previous studies in normal subjects have suggested that adrenergic blockade interferes with hepatic counter-regulation of hypoglycaemia only when glucagon secretion is suppressed by somatostatin [33]. Since diabetic subjects show impaired glucagon secretion [34] and, in some cases, reduced adrenaline elevations $[35,36]$ during insulin-induced hypoglycaemia, our finding that $\beta$-blockade has a more pronounced inhibitory effect on the hepatic response to adrenaline supports observations that propranolol may exacerbate hypoglycaemia in insulin-treated diabetes [37]. Our findings may also provide an explanation for the observation that $\beta$-blockade potentiates hypoglycaemia and blocks the rise in hepatic glucose production during exercise in diabetic but not in normal subjects [38]. Thus, the diabetics' inability to overcome $\beta$-blockade may render them more vulnerable to hypoglycaemia whenever the maintenance of hepatic glucose production is dependent on catecholamines.

Acknowledgments. We wish to thank J. Ligouri and S. Borghoff for technical assistance, P.Strumpf, M. Sacci and J.Janaro for their help in preparing the manuscript, M. Walesky, R. N. for her care of some of our patients, and Dr. R. Hendler for assistance in the hormonal measurements. This research was supported in part by grants AM-20541, AM-20495, RR50 and RR125 from the National Institutes of Health. Dr. Sherwin is the recipient of a Research Career Development Award (AM-00334) from the National Institutes of Health. This work was presented in part at the Annual Meeting of the American Diabetes Association, Washington, D.C., in June, 1980

\section{References}

1. Rizza R, Haymond M, Cryer P, Gerich J (1980) Differential effects of epinephrine on glucose production and disposal in man. Am J Physiol 237: E 356-E 362

2. Shamoon H, Hendler R, Sherwin RS (1980) Altered responsiveness to cortisol, epinephrine and glucagon in insulin-infused juvenile-onset diabetics. A mechanism for diabetic instability. Diabetes $29: 284-291$

3. Exton JH (1980) Mechanisms involved in $\alpha$-adrenergic phenomena: Role of calcium ions in actions of catecholamines in liver and other tissues. Am J Physiol 238 (Endocrinol Metab 1): E 3-E 12

4. Sutherland EW, Rall TW (1960) Relation of adenosine $3^{\prime}-5^{\prime}$ phosphate and phosphorylase to the actions of catecholamines and other hormones. Pharmacol Rev 12: 265-299 
5. Rizza RA, Cryer PE, Haymond MW, Gerich JE (1980) Adrenergic mechanisms for the effects of epinephrine on glucose production and clearance in man. J Clin Invest 65: 632-689

6. Deibert DC, DeFronzo RA (1980) Epinephrine-induced insulin resistance in man. J Clin Invest 65:717-721

7. Rizza RA, Haymond MW, Miles JM, Verdonk GA, Cryer PE, Gerich JE (1980) Effect of $\alpha$-adrenergic stimulation and its blockade on glucose turnover in man. Am J Physiol (Endocrinol Metab 1): E 467-E 472

8. Raveno WS, Rosenbaum H (1968) Propranolol and hypoglycaemia. Lancet 1: 920 (Letter)

9. Kotler MN, Berman L, Rubenstein AH (1966) Hypoglycaemia precipitated by propranolol. Lancet 2: 1389-1390

10. McAllister Jr RS (1976) Intravenous propranolol administration. A method for rapidly achieving and sustaining desired plasma levels. Clin Pharmacol Ther 20: 517-518

11. Shamoon H, Sherwin RS (1980) Epinephrine-induced hypoaminoacidemia in normal and diabetic humans: a $\beta$-adrenergic effect. Diabetes 29: $875-881$

12. Sherwin RS, Kramer KJ, Tobin JD, Insel PA, Liljenquist JE, Berman M, Andres R (1974) A model of the kinetics of insulin in man. J Clin Invest 53: 1481-1492

13. Passon PG, Peuler JD (1973) A simplified radiometric assay for plasma norepinephrine and epinephrine. Anal Biochem 51: 618-631

14. Hales CN, Randle PJ (1963) Immunoassay of insulin with insulin antibody precipitate. Biochem J 88: 137-146

15. Novak N (1965) Colorimetric ultramicro method for the determination of free fatty acids. J Lipid Res 6: 431-440

16. Wise JK, Hendler R, Felig P (1973) Influence of glucocorticoids on glucagon secretion and plasma amino acid concentrations in man. J Clin Invest 52: 2774-2782

17. Sacca L, Sherwin RS, Hendler R, Felig P (1979) Influence of continuous physiologic hyperinsulinemia in glucose kinetics and counterregulatory hormones in normal and diabetic humans. $\mathbf{J}$ Clin Invest 63:849-857

18. Heding LG (1975) Radioimmunological determination of human C-peptide in serum. Diabetologia 11: 541-548

19. Steele R (1959) Influences of glucose loading and of injected insulin on hepatic glucose output. Ann NY Acad Sci 82: 420-430

20. Eigler N, Sacca L, Sherwin RS (1979) Synergistic interactions of physiologic increments of glucagon, epinephrine and cortisol in the dog. A model for stress-induced hyperglycaemia. J Clin Invest 63: $114-123$

21. Cowan JS, Hetenyi Jr G (1971) Glucoregulatory responses in normal and diabetic dogs recorded by a new tracer method. Metab Clin Exp 20: 360-372

22. Radziuk J, Norwich KH, Vranic M (1978) Experimental validation of measurements of glucose turnover in non-steady state. Am J Physiol 234: E 84-E 93

23. Snedecor GW, Cochran WG (1967) Statistical methods, 6th edn. Iowa State University Press, Ames, Iowa, pp 93-119, 299-338

24. Gerich JE, Lorenzi M, Tsalikian E, Karam JH (1976) Studies on the mechanism of epinephrine-induced hyperglycaemia in man: Evidence for participation of pancreatic glucagon secretion. Diabetes $25: 65-71$
25. Sacca L, Hendler R, Sherwin RS (1978) Hyperglycaemia inhibits glucose production in man independent of changes in glucoregulatory hormones. J Clin Endocrinol Metab 47: 1160-1163

26. DeFronzo RA, Hendler R, Simonson D (1982) Insulin resistance is a prominent feature of insulin-dependent diabetes. Diabetes 31 : 795-801

27. Felig P, Gusberg R, Hendler R, Gump FE, Kinney JM (1974) Concentrations of glucagon and the insulin glucagon ratio in the portal and peripheral circulation. Proc Soc Exp Biol Med 147: $88-90$

28. Horwitz DL, Starr JI, Mako ME, Blackard WE, Rubenstein AH (1975) Proinsulin, insulin and C-peptide concentrations in human portal and peripheral blood. J Clin Invest 55: 1278-1289

29. Nickerson M, Kunos G (1977) Discussion of evidence regarding induced changes in adrenoceptors. Fed Proc 36: 2580-2583

30. Williams LT, Lefkowitz RJ, Watanabe AM, Hathaway DR, Besch Jr HR (1977) Thyroid hormone regulation of $\beta$-adrenergic receptor number. J Biol Chem 252: 2787-2789

31. Kunos G (1977) Thyroid hormone-dependent interconversion of myocardial $\alpha$-adrenoceptors in the rat. $\mathrm{Br} \mathrm{J}$ Pharmacol 59: 177-189

32. Olansky L, Jacobsson B, Pohl S (1981) Down regulation of $\beta$-adrenergic receptors by insulin in 3T3-L1 adipocytes. Clin Res 29: $871 \mathrm{~A}$

33. Clarke WL, Santiago JV, Thomas L, Ben-Galim E, Haymond MW, Cryer PE (1978) Adrenergic mechanisms in recovery from hypoglycemia in man: adrenergic blockade, Am J Physiol 5: E $147-\mathrm{E} 152$

34. Gerich JE, Langlois M, Noacco C, Karam JH, Forsham PH (1973) Lack of glucagon response to hypoglycemia in diabetes: evidence for an intrinsic pancreatic $\alpha$ cell defect. Science 182: 171-173

35. Popp D, Shah S, Cryer P (1982) Role of epinephrine-mediated $\beta$ adrenergic mechanisms in hypoglycemic glucose counterregulation in insulin-dependent diabetes mellitus. J Clin Invest 69: $315-326$

36. Kleinbaum J, Shamoon H (1983) Impaired counterregulation of hypoglycemia in insulin-dependent diabetes mellitus. Diabetes 32: $493-498$

37. Viberti GC, Keen H, Bloom SR (1980) $\beta$ Blockade and diabetes mellitus: Effect of oxprenolol and metoprolol on the metabolic, cardiovascular and hormonal response to insulin-induced hypoglycemia in insulin-dependent diabetics. Metabolism 29: 873-879

38. Simonson D, Sherwin R, DeFronzo R (1981) Adrenergic blockade alters glucose kinetics in diabetics during exercise. Diabetes 39 [Suppl] 1: 11 A

Received: 12 January 1983

and in revised form: 20 October 1983

Dr. Harry Shamoon

Albert Einstein College of Medicine

1300 Morris Park Avenue

Room 501, Forchheimer Building

Bronx, New York 10461, USA 